\title{
THE SURFACE ROUGHNESS OF THE MACHINED SURFACE OF MULTIAXIAL MILLING
}

\author{
Jan ZELINKA, Marek SADÍLEK, Pavel SZKANDERA, Ondřej MIZERA, Lenka ČEPOVÁ
}

VSB - Technical University of Ostrava, Ostrava, Czech Republic, EU, jan.zelinka.st@vsb.cz

https://doi.org/10.37904/metal.2019.908

\begin{abstract}
The main topic of the paper is the roughness analysis of machined surfaces shaped parts and influences that affect them. Specifically, it is an analysis of selected 2D and 3D roughness parameters by using the 3-axis, $3+2$-axis and 5-axis milling methods. In order to analyse the life of components and performances, the key requirement is the evaluation of surface roughness. In terms of $2 \mathrm{D}$ roughness, the most widely used parameters are $\mathrm{Ra}, \mathrm{Rz}$ and $\mathrm{Rq}$. In the case of $\mathrm{SD}$ roughness, namely Sa, Sz and Sq parameters. The current trend leads to continuous improvement measurement methods and instruments. Evaluation of Surface roughness involves various contact and noncontact methods. For this experiment, the material of aluminium alloy EN AW-6060 - AIMgSi0, 5 F19 was chosen. Sample sizes 40x40x25mm were selected. Samples were made on a universal 5-axis milling machine DMG MORI specifically DMU 50 with the Heidenhain iTNC 530 control system. The Milling centre is located in the laboratories of the Department of Machining, Assembly and Engineering Metrology of the Technical University of Ostrava. Surface roughness analysis was performed on a three-dimensional Alicona InfiniteFocus G5 microscope. With this optical meter, the surface topography was analysed in view of $2 \mathrm{D}$ and $3 \mathrm{D}$ surface roughness and waviness.
\end{abstract}

Keywords: Surface roughness, multiaxis milling

\section{INTRODUCTION}

Surface quality is a very important part of engineering production, to which customers demand more than before. [3] Surface structure characteristics, including the definition of parameters and their measurement, are part of the standards Geometrical Product Specifications (GPS). One of the common characteristics analyzed are roughness, waviness and base profile. [4] Surface roughness is also an important indicator for determining the quality and functionality of components manufactured by different manufacturing processes. Its size depends on the surface topography. [5]

The development of the aviation and automotive industries have brought new technological challenges because of increasing product complexity and new geometry modeled in CAD systems. These more complex geometries impose demanding manufacturing situations for milling molds and dies. For this reason, it is necessary to develop new milling technologies. In this way, CNC milling has become one of the strictest, most productive and most flexible manufacturing methods for complicated or shaped surfaces. [6] For machining complex shapes are used 5 -axis and $3+2$-axis milling, because some 3 -axis milling cannot be used to machine some surfaces. The use of tilt significantly affects the required surface roughness.

Surface roughness can be measured in two ways. Touch method and contactless method. [7] In this paper, the surface roughness measurement is carried out using non-contact method on the Alicona InfiniteFocus machine.

More and more parameters are used to evaluate the surface roughness so that the evaluation is objective and the parameters give sufficient information about the measured surface. The commonly used 2D parameters are Ra, Rq, Rz, Rp, Rv, Rc, Rk, Rt, Rmax, Rpk a Rvk. The standard ISO 4287 define these parameters. [7, 9] One of the main surface parameters assessed is RV. The Rv is mainly critical for fatigue-loaded components, such as springs. This creates the danger of stress concentration and subsequent crack formation see Figure 1. 


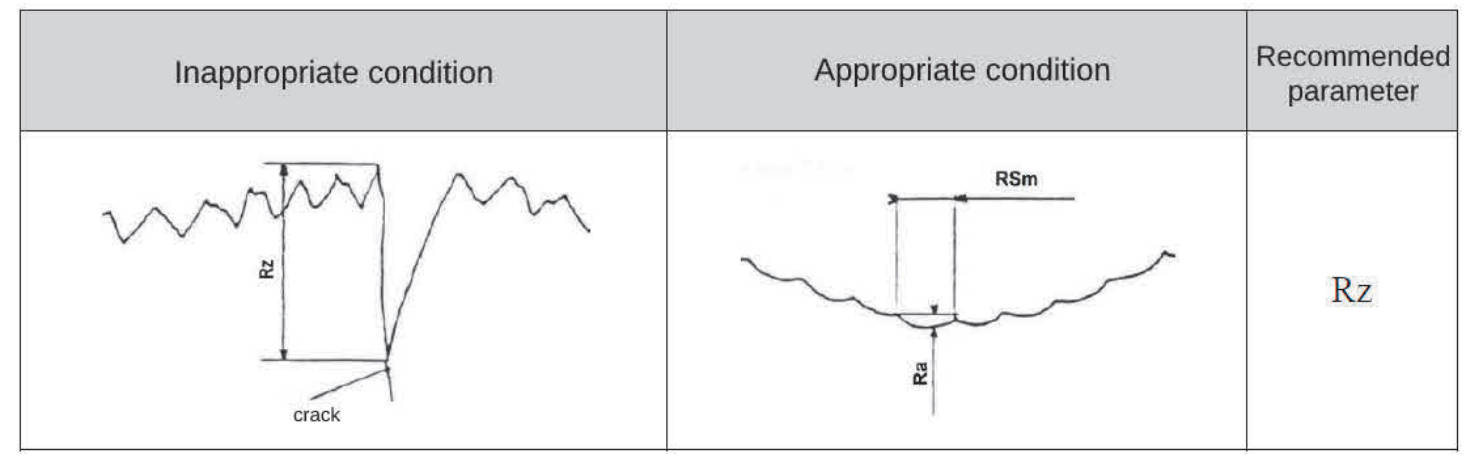

Figure 1 Example of fatigue stressed area [9]

Classical surface assessment using roughness profile parameters is not sufficient in many practical examples. More complex evaluation can be realized using parameters of so-called areal roughness. Such 3D parameters are Sa, Sq, Sz, Sv, Sp, Sz, Sk, Spk, Svk. Other usually analyzed parameters are volume parameters (Vmp, $\mathrm{Vmc}, \mathrm{Vvc}$ a Vvv). Volume parameters are calculated for the whole surface [1]. The group of volume parameters and their percentage forming bearing ratio curve, see Figure $\mathbf{2 a}$. In Figure $\mathbf{2 b}$ is shown one profile through the surface because of better visualization.

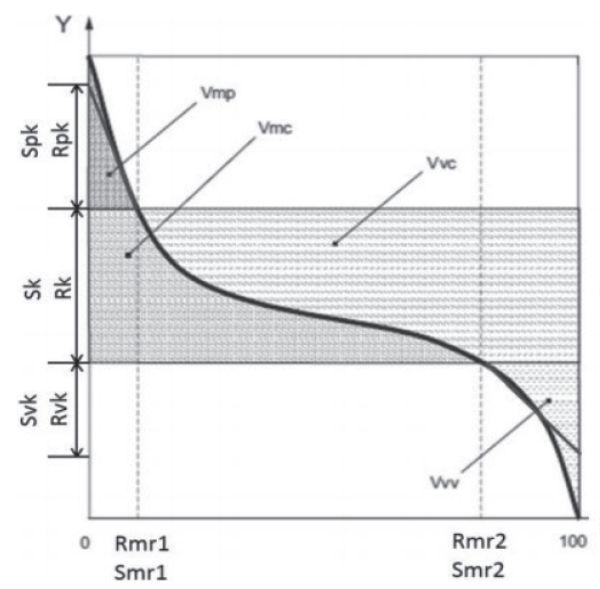

Figure 2a Bearing ratio curve [1]

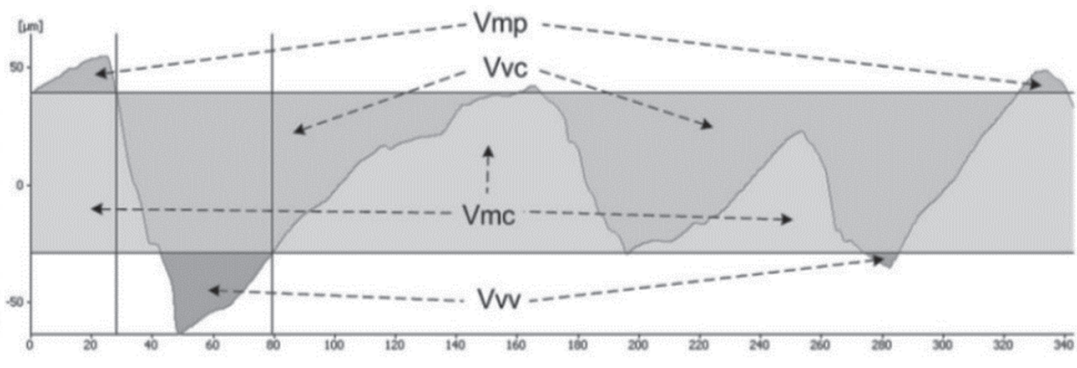

Figure $\mathbf{2 b}$ One profile through the surface [1]

3D parameters have better robustness and reliability compared to 2D parameters. [9] A more comprehensive description of the surface properties is beneficial to more detailed knowledge of surface and to the surface condition due to its functional behavior. [8]

\section{EXPERIMENT DESCRIPTION}

The aim of the experiment is to compare the two inclination angles of the milling cutter and their effect on the lowest values of surface roughness parameters. The sample proportions were $40 \times 40 \times 25 \mathrm{~mm}(\mathrm{w} \times \mathrm{d} \times \mathrm{h}$ ). The selected material of this sample is a well machinable aluminum alloy EN AW-6060 - AlMgSi0,5 F19. Samples were made on a universal 5-axis milling machine DMG MORI specifically DMU 50 with the Heidenhain iTNC 530 control system. The Milling centre is located in the laboratories of the Department of Machining, Assembly and Engineering Metrology of the Technical University of Ostrava. Surface roughness analysis was performed on a three-dimensional Alicona InfiniteFocus G5 microscope. The selected 2D and $3 \mathrm{D}$ surface roughness measurement area is marked in Figure $\mathbf{3 a}$ and Figure $\mathbf{3 b}$. Two production technologies were used: 3 -axis milling $\left(\beta f=0^{\circ}, \beta n=0^{\circ}\right)$ and 5-axis milling $\left(\beta f=0^{\circ}, \beta n=15^{\circ}\right)$. Selecting a certain tool axis position for 5 -axis milling was based on a random sample selection in the range of $\beta f=0^{\circ}$ to $20^{\circ}, \beta n=0^{\circ}$ to 
$20^{\circ}$. The Profile Length of $2 \mathrm{D}$ roughness was chosen $5 \mathrm{~mm}$. In case of 3D measure, the true area was $16 \mathrm{~mm}^{2}$. The number of Measured points were 82 082. The uncertainty of the measurement, which was $300 \mathrm{~nm}$, can be seen in the individual figures.

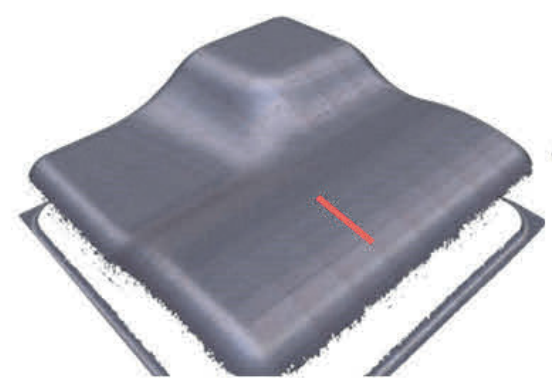

Figure 3a Measured area after 3-axis milling

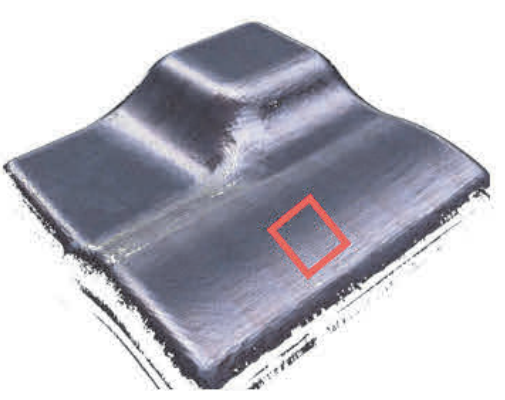

Figure 3b Measured area after 5-axis milling

By analyzing the measured values of roughness parameters in 2D roughness measurements, it can be stated that the values of 3-axis milling show much lower roughness than the values of 5 -axis milling. The following is a more detailed analysis of the individual parameters. If we analyze the Rv parameter and its results, it is desirable to have a higher measured value, which expresses the ability to retain more liquid. In this case, the higher roughness shows parameter measured of 5-axis milling. By comparing Rv and Rz it can be said their values are not similar, indicating that there may not be a risk of stress concentration, that would cause subsequent cracking. Rpk is desirable lower value due to higher dimensional accuracy during component operation. The Figure 4 shows that the lower value was measured for a component made using 3-axis milling. It is appropriate to analyze this parameter for components where shape accuracy is high. Conversely, a higher value is desirable for the Rvk parameter (reduced valley depth). A lower measured value, in extreme cases, can cause engine seizing. The measured higher value in this case was for the part made with 5 -axis milling.

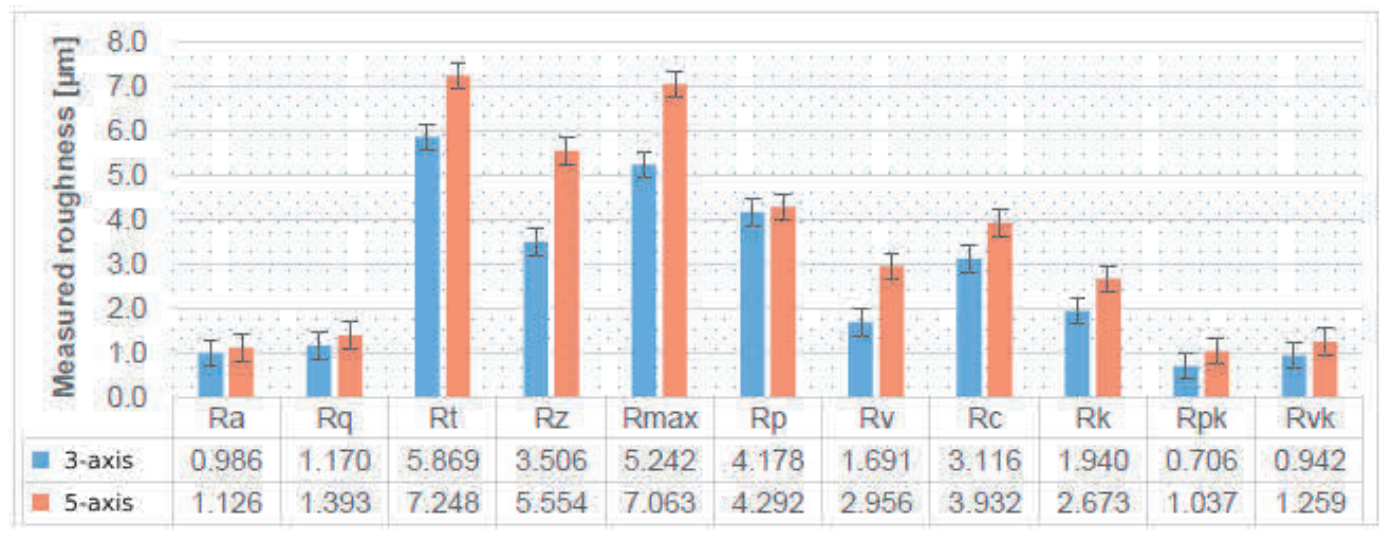

Figure 4 Evaluation of 2D roughness

The next parsed parameter is $\mathrm{Rp}$, which is used to predict the bearing characteristics (bearing surface characteristics) of the area. By comparing Rp and Rz is important a size of the difference, which indicates the degree of wear. It can be seen from the Table 1 that the 5-axis milling results are a lower due to a lower initial wear of the surface.

Table 1 Possible wear rate

\begin{tabular}{|c|c|c|c|}
\hline Milling method & $\begin{array}{c}\mathbf{R z} \\
(\boldsymbol{\mu \mathrm { m }})\end{array}$ & $\begin{array}{c}\mathbf{R p} \\
(\boldsymbol{\mu m})\end{array}$ & Ratio Rp/Rz \\
\hline 3-axis milling & 3.506 & 4.178 & 1.192 \\
\hline 5-axis milling & 5.554 & 4.292 & 0.773 \\
\hline
\end{tabular}


The measured roughness profiles of the individual components are shown in Figure 5 below. The curve on the top shows the roughness of the first component made with 3-axis milling, while the bottom curve shows the roughness profile after 5 -axis milling. If we compare the movement of both curves, clear differences can be identified. The profile of sample after 3-axis milling is less structured, consequently, the second component will have better lubrication properties and surface durability.

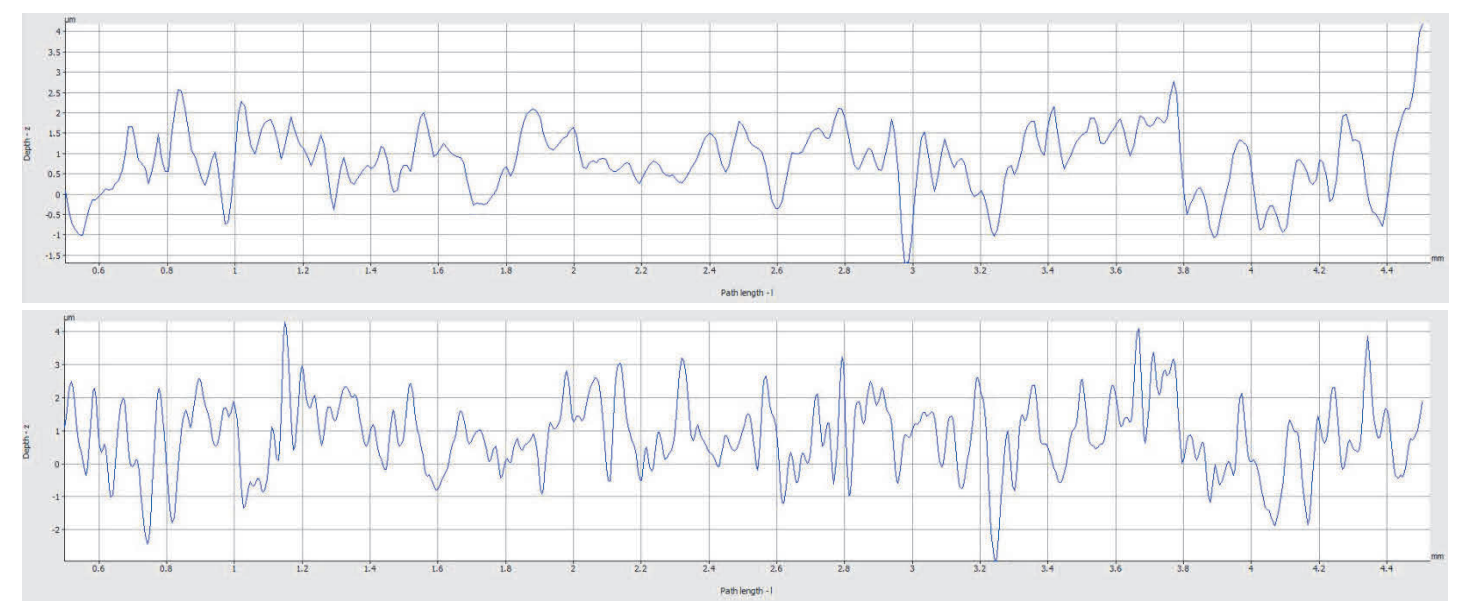

Figure 5 Extracted roughness profile

To compare the measured $2 \mathrm{D}$ and $3 \mathrm{D}$ roughness, we need to compare the values with the index $R$ and the values with the index $\mathrm{S}$. By comparing these results, it is clear that $2 \mathrm{D}$ roughness values are generally lower than in $3 \mathrm{D}$ roughness. The values of $\mathrm{Rq}$ and $\mathrm{Sq}$ are almost identical. This means that largest peak height measured in $2 \mathrm{D}$ are practically the same as $3 \mathrm{D}$. The greatest difference can be seen in the case of the parameters Rz vs. Sz. These parameters describe maximum height of the profile. The Rp and Sp describe maximum profile peak height. They were measured at same value in case of 3-axis milling. However, the difference is in the case of 5-axis milling, where is twice more higher. The Rv and Sv describe maximum profile valley depth. There is shown the surface measurement greater, because of better surface sensing.

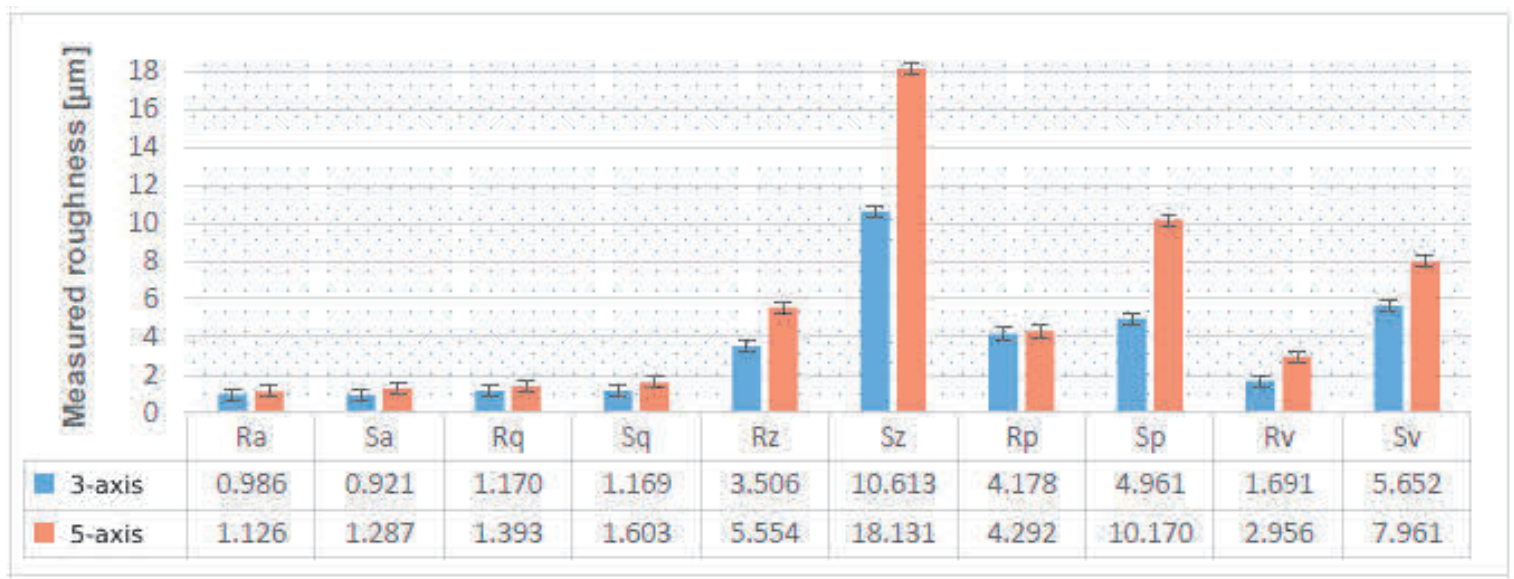

Figure 6 Evaluation of 2D and 3D roughness

One of the main prerogatives of 3D measurement is volume analysis. All measured volume parameters can be seen in Figure 7. By comparing them, it can be seen that with 5-axis milling all measured values are higher. The value of height parameter of the core (Sk) is much higher in case of 3-axis milling results. It is generally accepted to replace the Sz parameter to the Sk parameter in practice use, due to the fact that the influence of exceptional cases of very pronounced protrusions and depressions is not considered for the Sk parameter. 
The largest share of volume parameters has Vvc (Core void volume of the scale-limited surface). The Vmc parameter (core material volume of the scale-limited surface), is a higher value after 5 -axis milling. Almost the same value was measured for $\mathrm{Vvv}$.

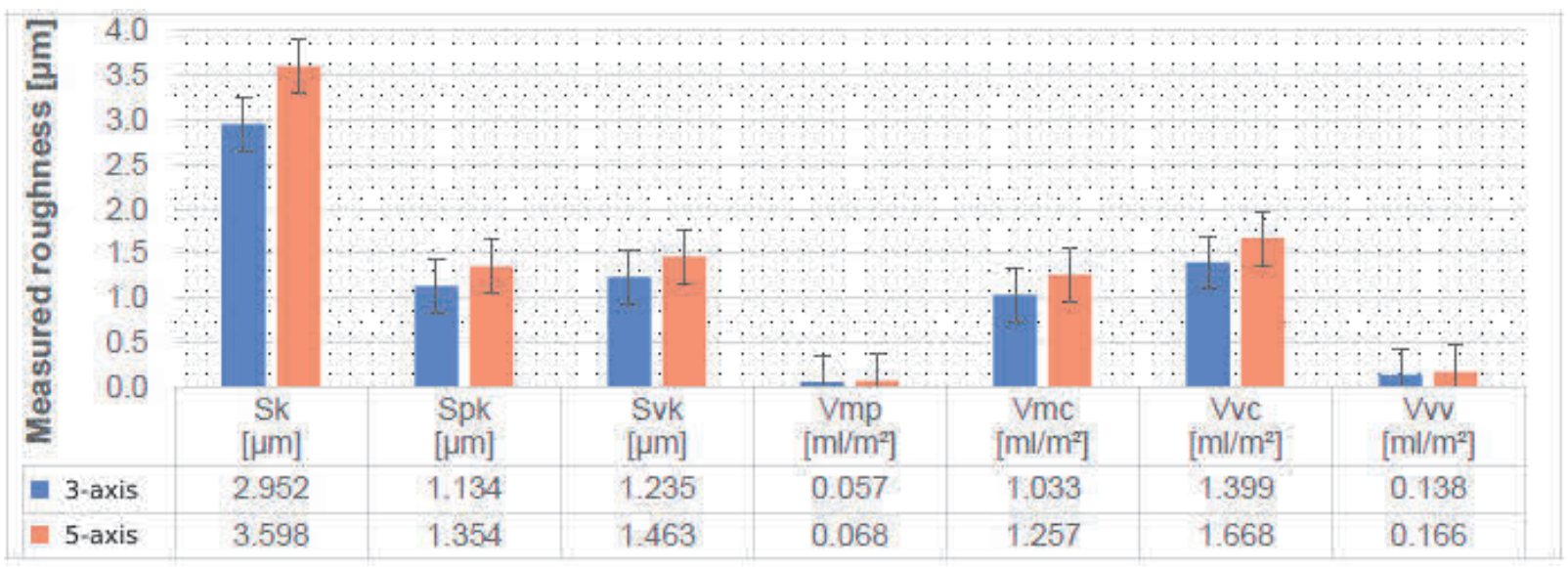

Figure 7 Evaluation of 3D volume parameters

Interesting to compare is the ratios Spk/Sk and Svk/Sk also. They express the ratio of protrusions or depressions to the roughness core. These ratios are shown below in Table 2. The ratio shows a slightly higher proportion of depressions to the roughness core.

Table 2 The ratio of projections and recesses to the roughness core

\begin{tabular}{|c|c|c|c|c|c|}
\hline Milling method & $\begin{array}{c}\text { Sk } \\
(\boldsymbol{\mu m})\end{array}$ & $\begin{array}{c}\text { Spk } \\
(\boldsymbol{\mu m})\end{array}$ & $\begin{array}{c}\text { Svk } \\
(\boldsymbol{\mu m})\end{array}$ & $\begin{array}{c}\text { Ratio } \\
\mathbf{S p k} / \mathbf{S k}\end{array}$ & $\begin{array}{c}\text { Ratio } \\
\text { Svk/Sk }\end{array}$ \\
\hline 3-axis milling & 2.952 & 1.134 & 1.235 & 0.384 & 0.418 \\
\hline 5-axis milling & 3.598 & 1.354 & 1.463 & 0.376 & 0.407 \\
\hline
\end{tabular}

The figures below show the 3D filtered surface of the components for 3-axis milling and 5-axis milling. In this case, the difference is visible, when the values on the left tend to be positive. On the other hand, the values on the right tend to be negative.

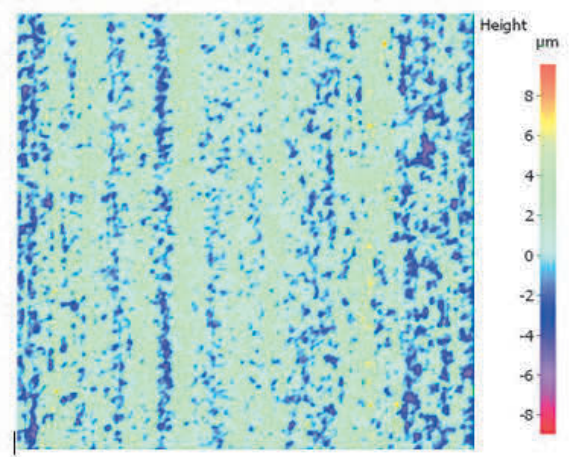

Figure 8a Filtered surface 3-axis milling

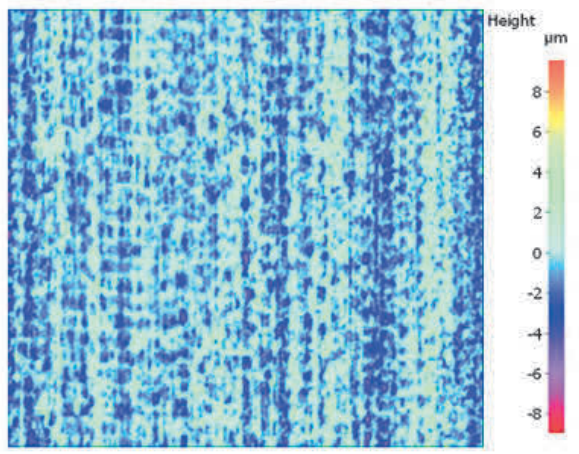

Figure 8b Filtered surface 5-axis milling

Another possible evaluation of the measured results is using a histogram. It shows us the frequency of measured values, see Figure 9 and Figure 10. The values in the picture are close to the theoretical Gaussian distribution. The top image shows the results for a 3-axis milling part and the bottom figure shows the 5-axis milling values. By comparing both histograms, the distribution in the lower picture is more direct. 


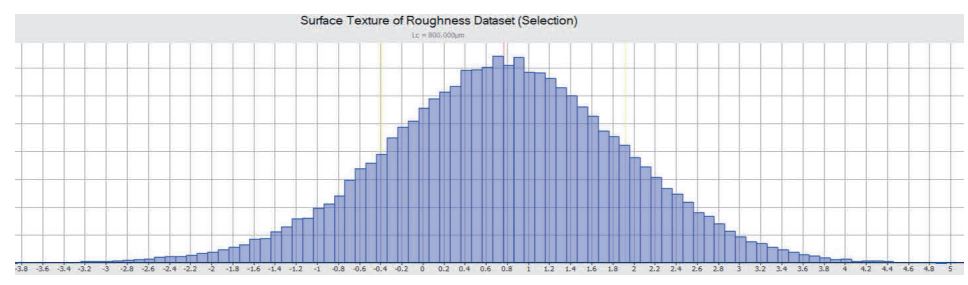

Figure 9 Surface texture of roughness dataset (3-axis milling)

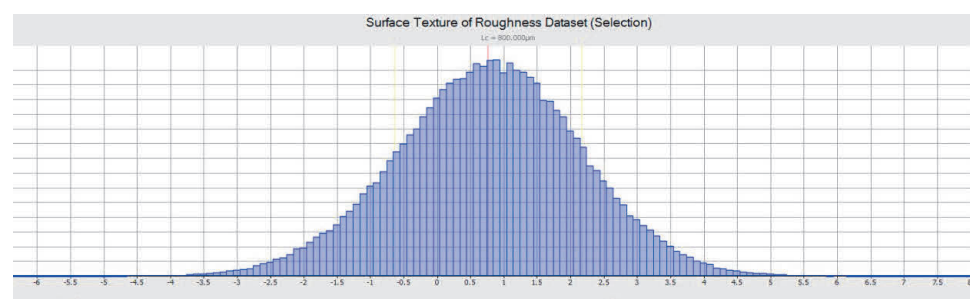

Figure 10 Surface texture of roughness dataset (5-axis milling)

\section{CONCLUSION}

Areal roughness parameters and volume parameters can obtained detailed information about researched surface. It is also possible to assess how the measured values differ from one another between the profile parameters and the area parameters. At first sight, the surface roughness values for 3 -axis milling seemed better. However, a more detailed analysis has shown that this milling method is not always appropriate. Depending on the functional properties, a better surface after 5 -axis milling appeared particularly. This surface had a better lubricating property and lower initial wear. When evaluating the shape accuracy, the surface was better after 3-axis milling.

\section{REFERENCES}

[1] BLATEYRON, F. In: Characterisation of Areal Surface Texture. Berlin, Heidelberg: Springer Berlin Heidelberg, 2013, Part 1: The Areal Field Parameters, chapter 2, pp. 15-43.

[2] LEACH, R. In: Characterisation of Areal Surface Texture. Berlin, Heidelberg: Springer Berlin Heidelberg, 2013, Part 1: Introduction to Surface Topography, chapter 1 pp. 1-13.

[3] ČEP, Robert; JANÁSEK, Adam; PETRŮ, Jana; SADÍLEK, Marek; MOHYLA, Petr; VALíČEK, Jan; HARNIČÁROVÁ, Marta; CZÁN, Andrej. Surface Roughness after Machining and Influence of Feed Rate on Process. Key Engineering Materials, 2014, Vol. 581, pp. 341-347.

[4] Progress in the measurement and evaluation of surface texture. Mmspektrum [online]. 2001, vol. 4, no. 1 [viewed 2019-05-17]. Available from: DOI: 010408.

[5] GOK, A., GOLOGLU C., DEMIRCI I. H. and KURT M. Determination of Surface Qualities on Inclined Surface Machining with Acoustic Sound Pressure. Strojniški vestnik - Journal of Mechanical Engineering. 2012, vol. 58, no. 10, pp. 587-597.

[6] ÇOLAK, O., KURBANOĞLU C. and KAYACAN M. Cengiz. In: Materials \& Design. Springer London, 2014, Part 1: Milling surface roughness prediction using evolutionary programming methods, chapter 77 pp. 657-666.

[7] JAIN, V. K. Nanofinishing science and technology: basic and advanced finishing and polishing processes. Boca Raton: CRC Press, 2016, p. 675.

[8] RAMMOHAN R., OMKUMAR M., IQBAL F. and JHA S. Evaluation of 2D and 3D Surface Roughness Parameters by MATLAB Algorithm in Ball End Magnetorheological Finishing Machine. In: Proceedings of 10th International Conference on Precision, Meso, Micro and Nano Engineering (COPEN 10). Chennai, 2017, pp. 675-679.

[9] VALICEK J., CEP R., ROKOSZ K., LUKIANOVIC C., KOZAK, D., ZELENAK M., KOSTIAL P., HLOCH S., HARNICAROVA M., HLAVACEK P and HALUZIKOVA B. New way to take control of a structural grain size in the formation of nanomaterials by extrusion. MATERIALWISSENSCHAFT UND WERKSTOFFTECHNIK, 2012, Vol. 43 , No. 5, pp. 405-411. 